\title{
Controle e segurança dos reatores nucleares
}

\section{ENTREVISTA COM CARLEY MARTINS}

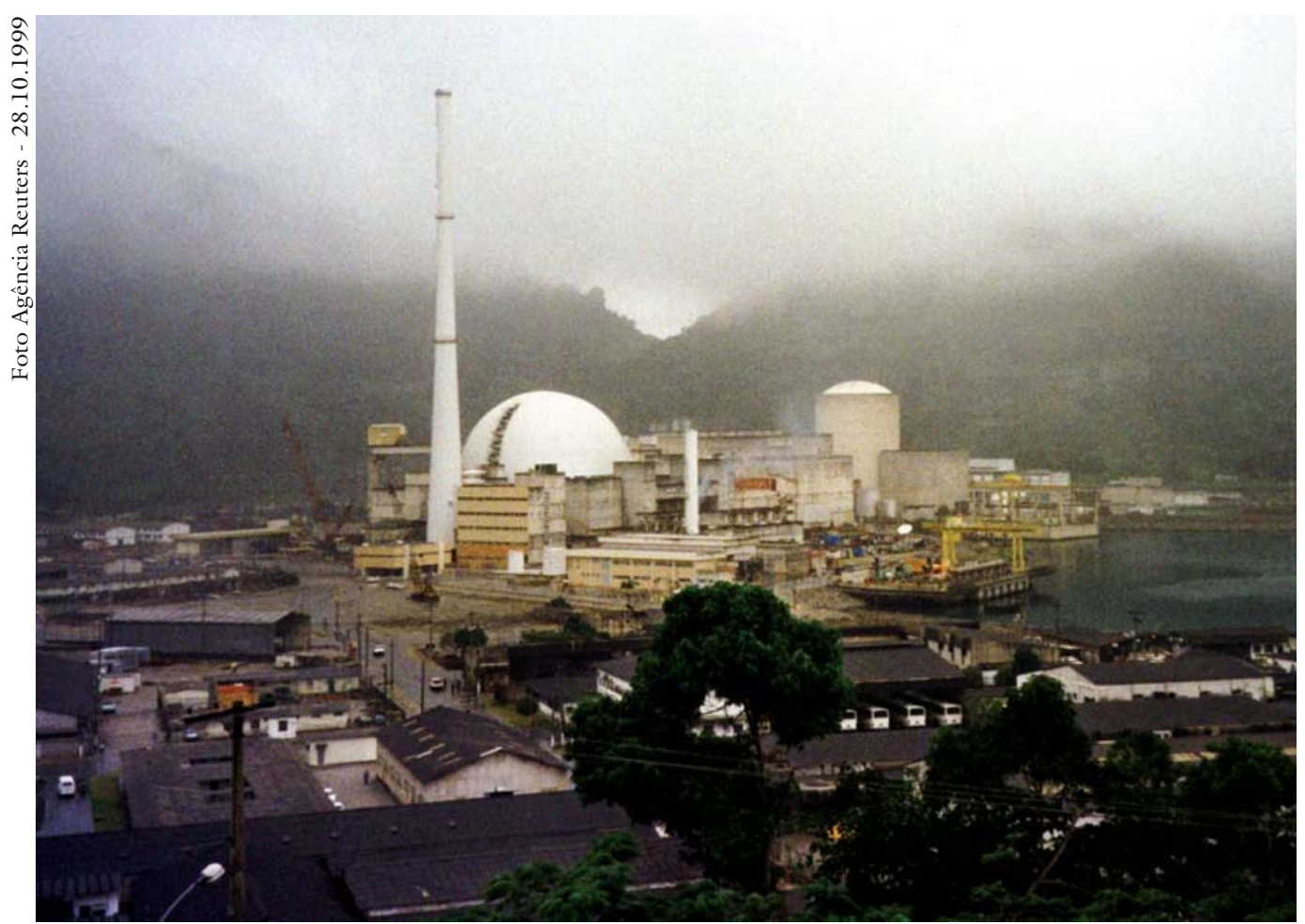

A Central Nuclear Almirante Álvaro Alberto, localizada na região de Angra dos Reis (RJ).

OMO NA ATUALIDADE há uma intensa polêmica a respeito da montagem da central nuclear Angra III, há um setor no governo que defende a construção de várias termelétricas utilizando energia nuclear, ESTUDOS AVANCADOS formulou algumas perguntas ao cientista Carley Martins, professor adjunto do Departamento de Física Nuclear e Altas Energias da Universidade Estadual do Rio de Janeiro (UERJ), como segue.

ESTUDOS AVANÇADOS - Os avanços recentes na evolução da ciência e da tecnologia eliminaram os riscos para a população em Angra dos Reis, resultantes da construção de uma nova central nuclear no litoral do Estado do Rio de Janeiro?

Carley Martins - Sim, em minha opinião, não há riscos significativos para a população de Angra dos Reis decorrentes da construção de uma nova usina no Complexo Nuclear Almirante Álvaro Alberto. A tecnologia existente permite 


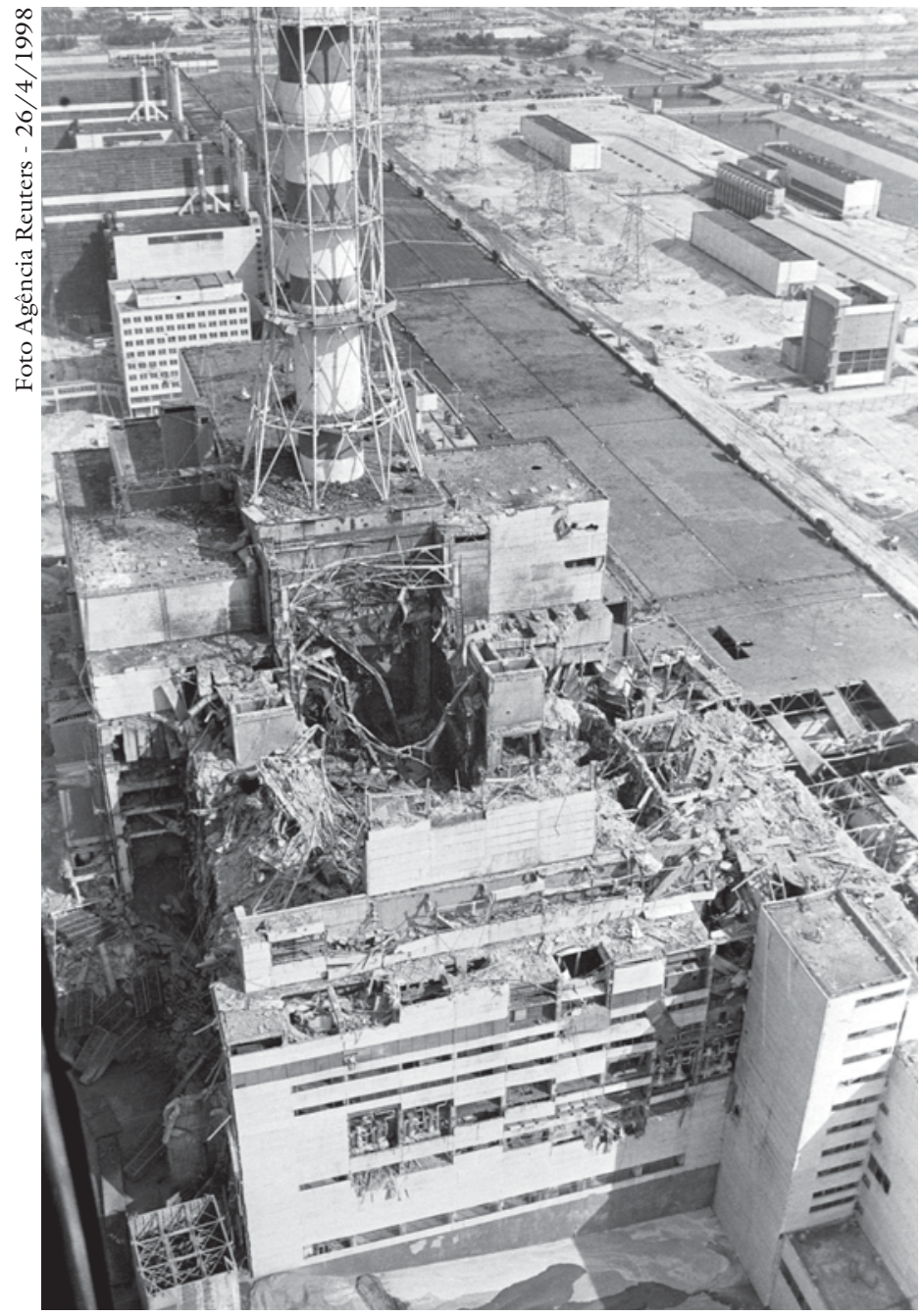

$O$ desastre nuclear de Chernobyl.

reduzir a valores desprezíveis a probabilidade de ocorrência de falhas graves no núcleo, nos sistemas de controle e de operação dos reatores. Os sistemas de controle e segurança dos reatores nucleares são desenvolvidos utilizando todos os recursos tecnológicos disponíveis à época de sua concepção e obedecem a rígidas normas de fabricação e de certificação, determinados por organismos internacionais. Mesmo nos reatores mais antigos, esses dispositivos são quase "à prova de falhas". Por exemplo, o reator de Angra I do Complexo Nuclear Almirante Álvaro Alberto, construído com tecnologia dos anos 1970, teve um início de operação conturbado, com problemas que descontinuaram a geração de energia em diversas oportunidades, mas nenhum deles associado ao núcleo, a região mais crítica e, portanto, a mais protegida do reator. Além de tecnologicamente evoluídos, os dispositivos de proteção ao núcleo dos reatores são constituídos por sistemas redundantes, existindo mais de um circuito de proteção a um mesmo componente do reator. Na eventualidade de falha de um dos circuitos, o outro entra em ação de imediato, reduzindo desse modo a probabilidade de evolução temporal de uma eventual disfunção do sistema. Em uma rápida consulta à história da energia nuclear, podemos observar que os acidentes mais significativos que ocorreram com reatores nucleares foram decorrentes de falhas de operação, com intervenções equivocadas ou erros em procedimentos de teste do reator. Foi assim com Three Mile Island, nos Estados Unidos, em 1979, e com Chernobyl, na Rússia, em 1986. No primeiro caso, operadores desligaram equivocadamente um sistema de proteção do reator, permitindo uma excursão de temperatura no núcleo. No segundo, dispositivos específicos de segurança foram desligados, 


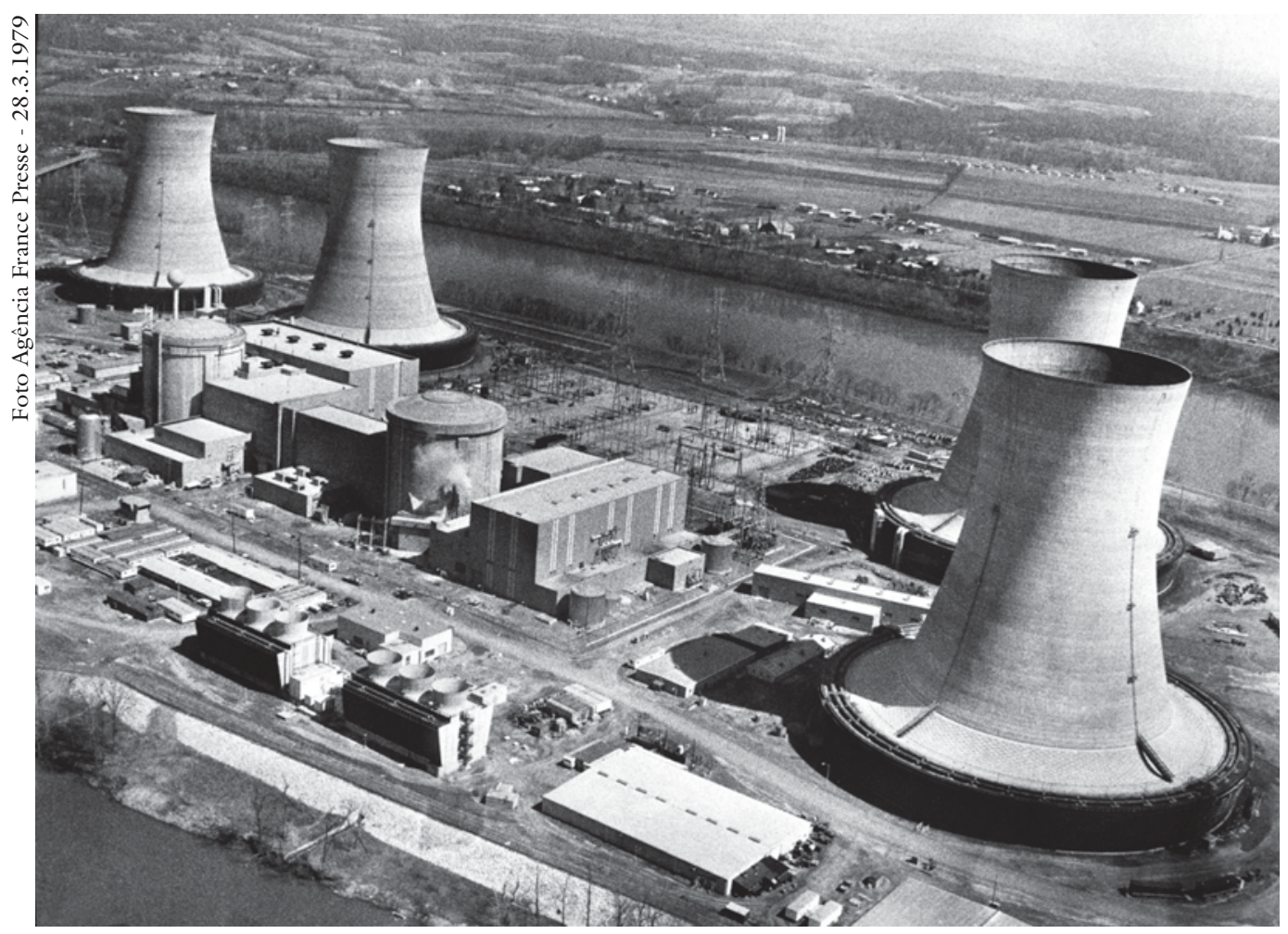

A usina nuclear de Three Mile Island, na Pensilvânia (EUA): derretimento parcial do reator.

para o estudo de um perfil de acidente. Os operadores não souberam identificar o tempo próprio de intervenção no sistema e, após uma seqüência de erros, perderam o controle do reator. Cabe ressaltar que a unidade do complexo nuclear de Chernobyl, responsável pelo acidente, era um reator de tecnologia totalmente ultrapassada, que já não deveria estar funcionando naquela época. Portanto, se levarmos em conta os mais de quatrocentos reatores nucleares em funcionamento no mundo e o reduzido número de acidentes significativos ocorridos ao longo dos anos, podemos concluir que a história da geração de energia pela fissão do núcleo atômico é muito satisfatória, tendo os especialistas da área um aprofundado conhecimento técnico e científico dessa tecnologia. Reafirmo, portanto, meu ponto de vista inicial de que a usina de Angra III será muito bemvinda e contribuirá com os seus megawatts para o crescimento deste país, sem um significativo acréscimo de risco à população da região de Angra.

ESTUDOS AVANÇADOS - Ante a possibilidade de acidentes e outras anormalidades no funcionamento de usinas nucleares, normas internacionais estabelecem medidas preventivas que devem ser rigorosamente observadas a fim de proteger a população que vive na área onde estão sediadas essas centrais elétricas. No caso de Angra I e II, essas providências e esses planos preventivos correspondem às necessidades de garantir a segurança dos que residem no Estado do Rio de Janeiro?

Carley Martins - Esse é, na minha opinião, o grande pesadelo para quem vive naquela área, mesmo levando em conta a baixíssima probabilidade de even- 


\section{“O acesso por terra à região da usina é feito por meio da BR 101, o que, em épocas de chuva intensa, é grande o risco de desmoronamento de barreiras. $O$ acesso por mar seria a única alternativa em caso de interdição da rodovia."}

tos graves com os reatores de Angra. Desde o início da operação de Angra I, na primeira metade dos anos 1980, essa questão vem sendo discutida e negociada com os administradores da cidade de Angra, sem jamais ter sido estabelecido um plano de evacuação seguro da população que vive no entorno da região. O acesso por terra à região da usina é feito por meio da BR 101, o que, em épocas de chuva intensa, é grande o risco de desmoronamento de barreiras. $\mathrm{O}$ acesso por mar seria a única alternativa em caso de interdição da rodovia. Mas não se tem conhecimento de um plano organizado nesse sentido. Então, sob esse aspecto, a Central Nuclear de Angra dos Reis continua em débito com a população da região.

ESTUdOS AVANÇADOS - Não é um erro a empresa responsável pela operação de uma usina nuclear simultaneamente ser a encarregada de fiscalizar o cumprimento das normas de segurança de uma central, como sucede com Angra I e II?

Carley Martins - A operadora dos reatores da central nuclear de Angra é a Eletronuclear, empresa vinculada ao Ministério de Minas e Energia. O órgão licenciador, regulador e fiscalizador de toda atividade nuclear no Brasil é a Comissão Nacional de Energia Nuclear, vinculada ao Ministério de Ciência e Tecnologia. São empresas vinculadas a ministérios distintos, e, portanto, podemos entendê-las como empresas independentes. No que tange a salvaguardas nucleares, isto é, no cumprimento de medidas destinadas à proteção e ao controle de material nuclear, existente em qualquer planta ou instalação do chamado ciclo do combustível nuclear e fruto de acordos internacionais, nossas usinas são fiscalizadas pela Agência Brasileiro-Argentina de Contabilidade e Controle de Material Nuclear (ABACC) e pela Agência Internacional de Energia Atômica (AIEA). Portanto, os graus de liberdade da operadora das usinas de Angra são determinados por essas agências/comissões fiscalizadoras.

Carley Martins é professor adjunto no Departamento de Física Nuclear e Altas Energias, na Universidade do Estado do Rio de Janeiro. @ - cmartins@fnal.gov 